\title{
Experimental and Numerical Investigation of the Effect of Standing People on Dynamic Properties of a Beam-Like Bridge
}

\author{
Wei He, ${ }^{1,2}$ Weiping Xie, ${ }^{1}$ and Lisheng Liu ${ }^{2}$ \\ ${ }^{1}$ School of Civil Engineering and Architecture, Wuhan University of Technology, Wuhan 430070, China \\ ${ }^{2}$ Department of Mechanics and Engineering Structure, School of Science, Wuhan University of Technology, Wuhan 430070, China \\ Correspondence should be addressed to Wei He; heweismile@126.com
}

Received 28 July 2017; Revised 17 October 2017; Accepted 31 October 2017; Published 15 November 2017

Academic Editor: Oleg V. Gendelman

Copyright (c) 2017 Wei He et al. This is an open access article distributed under the Creative Commons Attribution License, which permits unrestricted use, distribution, and reproduction in any medium, provided the original work is properly cited.

\begin{abstract}
This paper studies the vertical dynamic properties of a beam-like bridge attached with standing people. A purpose-built lively bridge was constructed. Model properties of the empty structure are obtained using ambient vibration testing method. Experimental tests of the bridge attached with standing people were also conducted covering a variety of densities of occupants and different postures. The considerable number of participants and repetitions makes it possible to take into account inter- and intrasubject variability. To illustrate the variations of dynamic properties of the structure, a mathematic model of standing people-structure interaction system is developed employing the single degree-of-freedom (SDOF) human body model. It is shown that the model developed herein can effectively illustrate the experimental observations. Based on the model, the effect of damping and natural frequency of the human body on dynamic properties of the occupied structure is scrutinized. Results show that the modal properties of the human body contribute remarkably to the structural damping but little to the structural natural frequencies.
\end{abstract}

\section{Introduction}

Human-structure interaction (HSI), first introduced by Griffin [1], has become a consensus and frontier research area both in biomechanical engineering and in civil engineering communities. Extensive research interest has mounted on the modeling of HSI phenomenon, aimed at obtaining a better illustration of in site or experimental observations in lateral (Fujino et al. [2]; Dallard et al. [3, 4]; Macdonald [5]) or in vertical vibrations (Ellis and Ji [6]; Falati [7]; Brownjohn [8]; Sachse et al. [9]; Brownjohn et al. [10]; Zivanovic et al. [11]; Reynolds and Pavic [12]; Silva and Thambiratnam [13]; Jones et al. [14]; Salyards et al. [15, 16]; An et al. [17]; Dey et al. [18]) of slender flexible structures.

Some remarkable experimental work, either in laboratory or in real-life structures, has yielded results indicating variations in frequencies (decrease or increase) and an increase in structural damping of the occupied structure. The changes on dynamic properties mainly depend on natural frequency of the structure, the posture of the occupants, and the mass ratio of occupants to structure. As a matter of fact, the interaction between human body and structure may effectively change the characteristics of the system, especially for large mass ratio cases [6]. A better understanding of the dynamic characteristics of crowd-occupied structures will be helpful to structural design and vibration control of these structures, especially if vibration serviceability is controlling the design.

Generally, there are two representative models of the vertical human body. One considers the body as spring-massdamper (SMD) systems. This model is based on experimental observations of frequency response functions (FRFs) of vertical human body. It has been experimentally demonstrated that an individual or a crowd acts at least as a single degreeof-freedom (SDOF) system when the individual or crowd is stationary, such as sitting or standing $[19,20]$. SDOF human model is widely adopted although multi-degree-of-freedom model may improve the results of simulation $[21,22]$. The other model is called continuous bar model. In 1995, Ji [23] proposed a biomechanical continuous bar model to simulate the vertical vibration of human body. This model gives an alternative to modeling HSI and has been adopted by Zhou et al. $[24,25]$ in their recent research. Compared with the SDOF model, the rationality of the bar model has not been experimentally verified. Moreover, the continuous bar model 
is more complicated in computation and it is difficult to determine the distributed stiffness and damping parameters of the human body.

Corresponding to the human body model, there are two representative methods of modeling the vertical vibration of HSI. One is called separated modeling method [25], which considers the structure and the crowd as independent SDOF system, and the crowd-occupied structures could be treated as the damped 2-degree-of-freedom (2DOF) representations [26]. This model is efficient in qualitatively illustrating the variations of dynamic properties of crowd-occupied structures. However, as the structure is simplified as a SDOF system, the model basically ignores the effect of higher modes and cannot consider the effect of distribution of crowds. The other method of modeling the vertical vibration of HSI is called integrative method [25]; that is, the body and the structure are treated as an inseparable whole. Zhou et al. [25] developed a 2 DOF system to describe the coupled vibration of the body and the structure, in which one degree is from the human body and the other degree from the structure. It is worth noting that this method also ignores the contribution of higher modes of the structure and cannot consider the effect of distribution of crowds. Moreover, it is challenging to determine the parameters of the model, especially the coupled mass and stiffness and damping parameters.

This paper studies the vertical dynamic characteristics of a beam-like bridge attached with standing people via both experimental and theoretical modeling work. A detailed experimental test was conducted for both the empty bridge and the bridge occupied with different sizes of participants. To illustrate the experimental observations, a coupled model of standing people-bridge interaction system is developed, in which the bridge is modeled as a simply supported beam and the human body as SDOF spring-mass-damper system. Based on the model, the effect of modal properties of the human body on dynamic properties of the occupied structure is considered in detail. The main objective of this study is twofold: (1) part of it is to examine the capability of the proposed model in modeling the HSI; (2) the authors hope the comparatively detailed experimental work can help in a better understanding of the HSI and enriching the current experimental database on this issue, especially for lightweight bridges.

The paper is structured as follows. Section 2 describes the details of the experiment. The problem concerned herein is formulated in Section 3. The effectiveness of the proposed model is examined in Section 4. Based on the model, the effect of the standing people on dynamic properties of the structure is investigated through numerical examples covering a range of parameters.

\section{Experiment}

2.1. Description of the Test Bridge. A flexible, lightweight bridge (see Figure 1) was constructed for the experimental investigation. The bridge is $10.5 \mathrm{~m}$ long in length and $1 \mathrm{~m}$ in width. A composite (steel-concrete) cross section is employed in the design. The composite cross section consisted of two steel I-section beams HW100 × $100 \times 6 \times 8$ (depth $\times$ flange width $\times$ web thickness $\times$ flange thickness) and a $120 \mathrm{~mm}$ thick deck made of class 30 concrete. A $6 \mathrm{~mm}$ thick antiskid steel plate welded on top of the I-profile beam was also utilized serving as formwork when casting concrete. The composite action is achieved by means of shear studs (diameter $12 \mathrm{~mm}$, length $75 \mathrm{~mm}$ ) welded to the steel plate on top of the two beams. To provide full interaction between the steel and concrete, the studs are spaced at $250 \mathrm{~mm}$. The span length of the bridge is $10.3 \mathrm{~m}$. The total mass of the bridge is $3500 \mathrm{~kg}$.

2.1.1. Modal Properties of the Bridge. Modal tests using ambient vibration method $[27,28]$ were performed. Previous modeling of the structure indicates that the first lateral frequency of the bridge is over $18 \mathrm{~Hz}$. In the present study, only the vertical vibration is concerned.

Measurement points were chosen to both sides of the bridge and a total of 38 locations $\sim 19$ points per side were selected. The accelerometers were installed on the surface of the bridge in the vertical directions. Figure 2 shows the location of the measuring points on the bridge. Bruel \& Kjaer 4507B piezoelectric accelerometers, having a nominal sensitivity of $1 \mathrm{mV} / \mathrm{g}$ and the frequency range from $0.3 \mathrm{~Hz}$ to $6000 \mathrm{~Hz}$, were employed for response measurements. The data were acquired using PULSE data acquisition software. The sampling frequency is $200 \mathrm{~Hz}$. The duration of the recording period is one hour which ensures efficient length of test data.

The stochastic subspace identification (SSI) method (Overschee and de Moor [29, 30]; Peeters and de Roeck [31]; Ren et al. [32]) was employed for modal parameter identification. The data processing and modal parameter identification were carried out using Matlab software.

Table 1 summarizes the dynamic characteristics of the bridge identified from ambient vibration test data. The mode shapes of the bridge are shown in Figure 3. It can be seen from Table 1 that the bridge has a very low vertical frequency, light damping, and light weight. Note that the 2 nd and 3 rd vertical vibration frequencies are 3.92 and 8.37 times, respectively, of that of the 1st mode, which indicates that the bridge behaves closely to an ideal simply supported beam (in that case, 4 and 9 times, respectively).

2.1.2. Numerical Modeling of the Bridge. A finite element (FE) model of the bridge (Figure 4) was developed employing beam and shear elements in ANSYS software for further investigation of the problem. The steel I-profile beams were modeled using 3D BEAM4 elements. The concrete deck and the supporting steel plate were modeled using orthotropic SHELL63 elements assuming isotropic properties. These elements are capable of transferring both in-plane and out-ofplane loads. The steel shear studs were not incorporated in the FE model to reduce the number of elements. The beam and the deck were assumed to be closely bonded during vibration. Modeling parameters: Young's modulus for steel and concrete is 200 and $30 \mathrm{GPa}$, respectively; material density for steel and concrete is 7850 and $2600 \mathrm{~kg} / \mathrm{m}^{3}$, respectively; and Poisson's ratio for steel and concrete is 0.3 and 0.2 , respectively. Supports at both ends of the bridge were modeled as pinned, but with a possibility of sliding free in the longitudinal 


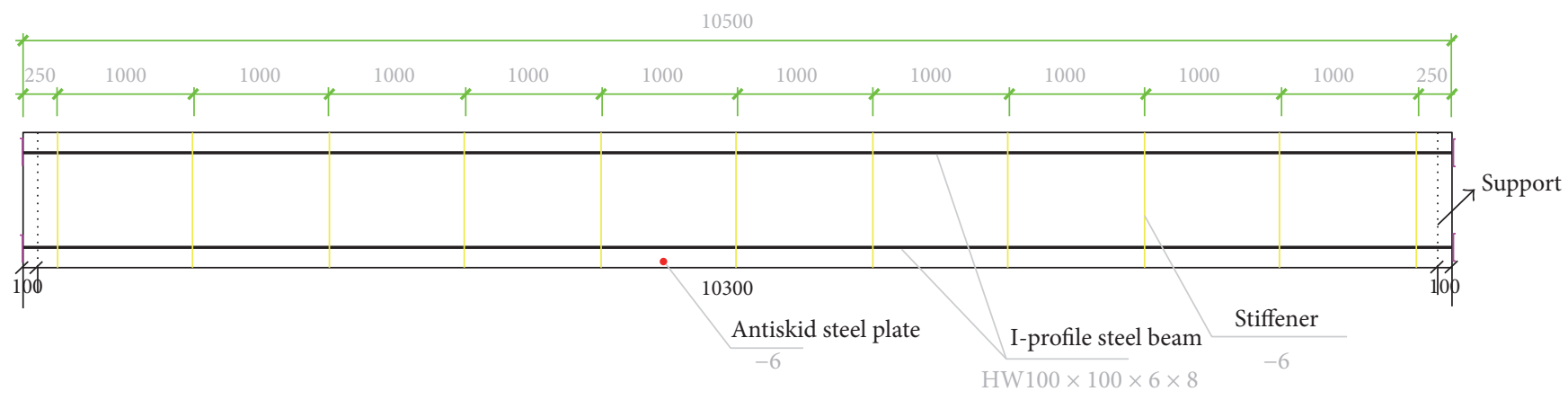

(a) Plane view

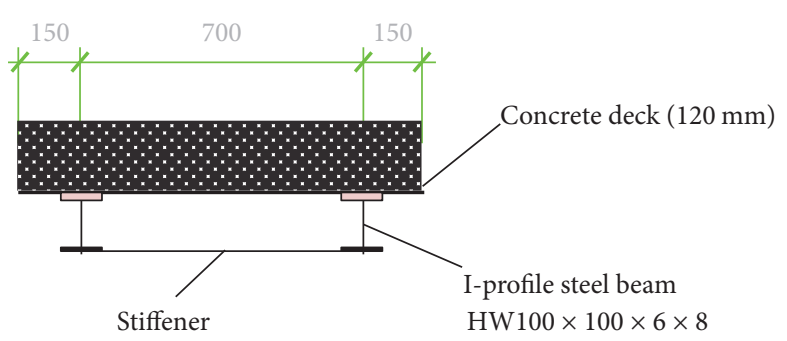

(b) Cross section

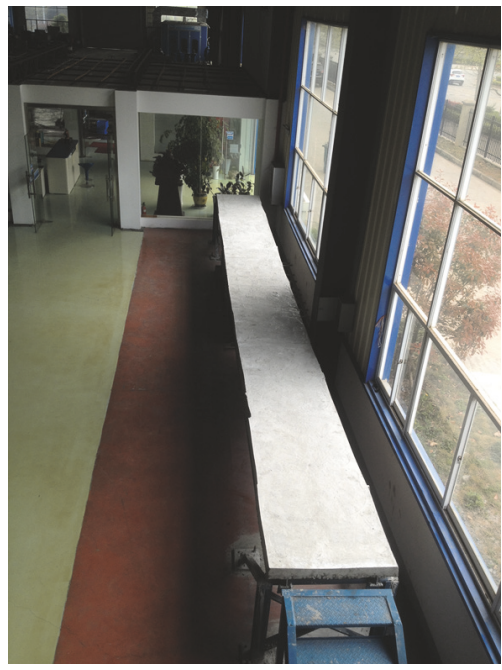

(c) Real structure

Figure 1: Configuration of the test bridge (all dimensions in $\mathrm{mm}$ ).

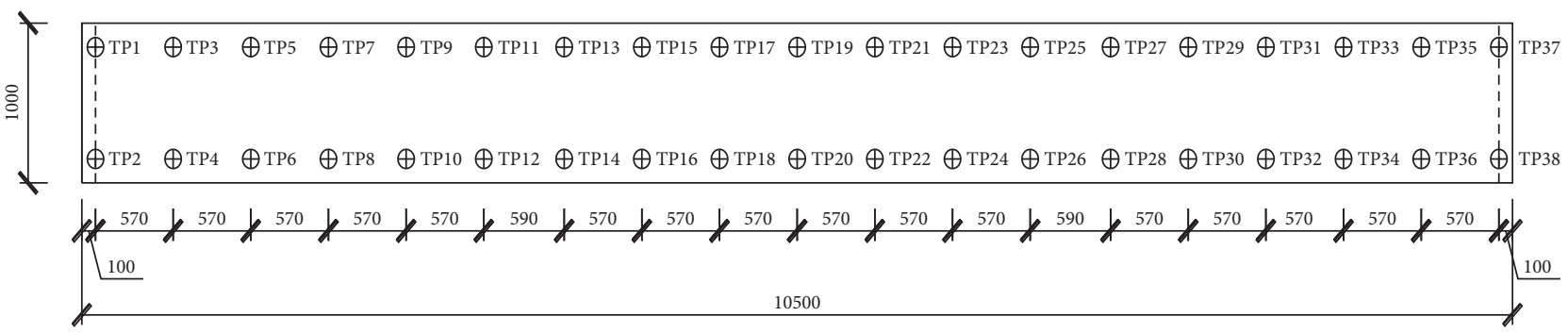

FIGURE 2: Deployment of sensors for modal test (all dimensions in $\mathrm{mm}$ ).

TABle 1: Dynamic characteristics of the bridge.

\begin{tabular}{lccc}
\hline Mode number & & Test bridge (total weight 3500 kg) \\
Damping ratio (\%) & 0.42 & Mode description \\
\hline 1 & Frequency $(\mathrm{Hz})$ & 0.43 & 1st bending \\
2 & 2.83 & 0.53 & 2nd bending \\
3 & 10.84 & 0.60 & 1st torsion \\
4 & 19.92 & 3rd bending \\
\hline
\end{tabular}




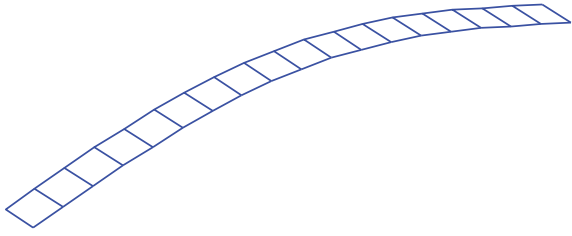

(a) 1st vertical mode, $f_{v, 1}=2.83 \mathrm{~Hz}$

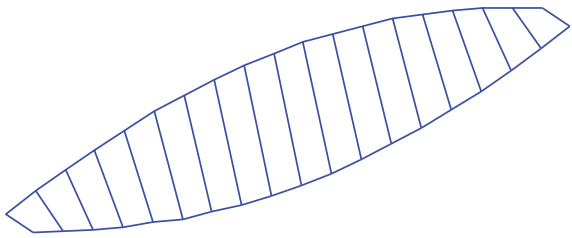

(c) 1st torsion mode, $f_{t, 1}=19.92 \mathrm{~Hz}$

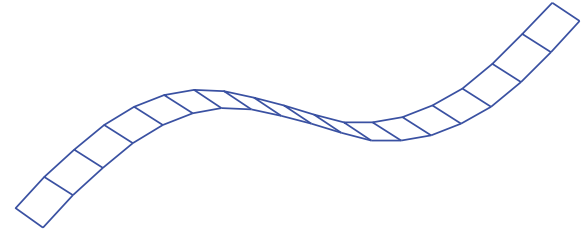

(b) 2nd vertical mode, $f_{v, 2}=10.84 \mathrm{~Hz}$

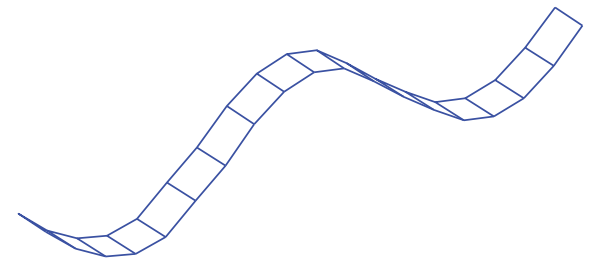

(d) 3rd vertical mode, $f_{v, 3}=23.24 \mathrm{~Hz}$

FIGURE 3: Four modal shapes identified from modal test results.

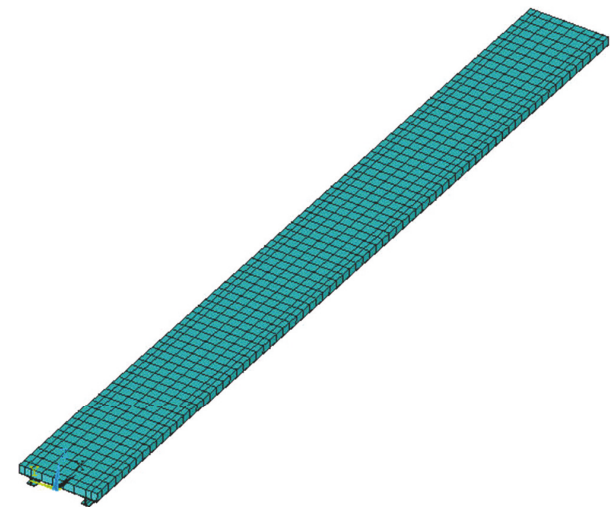

(a)

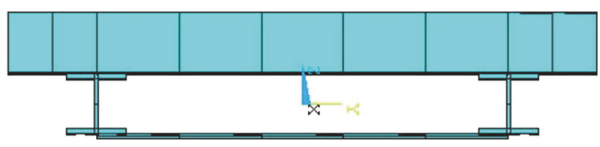

(b)

FIgURE 4: FE model of the bridge. (a) 3D model and (b) cross section.

direction. Specifically, all the translational degrees of freedom were restricted for one support, while only the vertical and the lateral translational degrees of freedom were restricted for the other support. The FE model of the bridge has 887 elements and 780 nodes in total. Modal properties of the structure were obtained by modal analysis using the finite element model (shown in Figure 5). Comparison between Figures 3 and 5 indicates a good match between the numerical modeling and the experimental results.

\subsection{Experimental Setup}

2.2.1. Test Subjects. Twenty-three test subjects (TSs), twentyone males and two females, volunteered to participate in the experiments. The general characteristics of the TSs, in terms of the average \pm one standard deviation, are age $21.0 \pm 1.2$ years, height $1.73 \pm 0.07 \mathrm{~m}$, and mass $68.1 \pm 12.5 \mathrm{~kg}$. Their basic properties are presented in Table 2.

2.2.2. Test Cases. Two different postures of TSs were considered in the experiment: (1) standing with straight knees and (2) standing with bent knees. Numbers of TSs including 1,
$3,5,7,9,13$, and 15 persons on the bridge were also taken into account in the experiments, resulting in a range of mass ratios.

The positions of test subjects of various crowd sizes were given in Figure 6. TSs were positioned symmetrically with respect to the mid-span of the bridge at an equal distance of $0.7 \mathrm{~m}$ so they can behave freely. Besides, all test subjects were involved in single-person tests to account for intersubject variability.

To get a stronger excitation of the structure and improve the quality of test signals, the heel-impact method was employed. Previous studies indicated that heel-impact method can successfully reveal the dynamic behavior of structures [33, 34]. For straight-knees posture, TSs were instructed to raise their heels and stand on tiptoe (Figure 7(a)) and then drop their heels suddenly and keep knees straight simultaneously (Figure 7(b)), while for bent-knees posture TSs were instructed to bend their knees as heels dropping (Figure 7(c)). A metronome was used to guide the TSs in same pattern during the tests. Before the experiment started, prior training was performed to ensure that TSs were familiar with the testing process. Each test was repeated five times. 


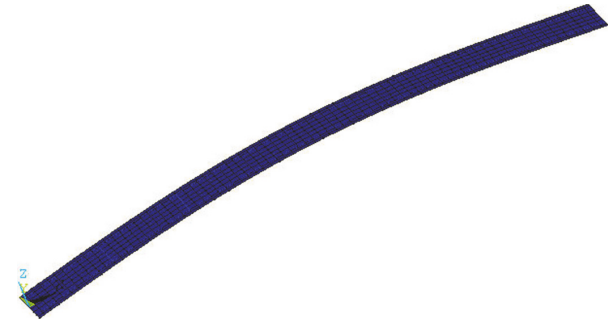

(a) 1 st vertical mode, $f_{v, 1}=2.82 \mathrm{~Hz}(-0.4 \%)$

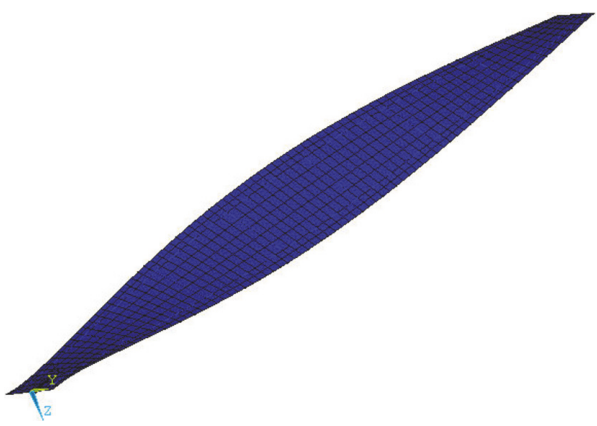

(c) 1st torsion mode, $f_{t, 1}=19.17 \mathrm{~Hz}(-3.8 \%)$

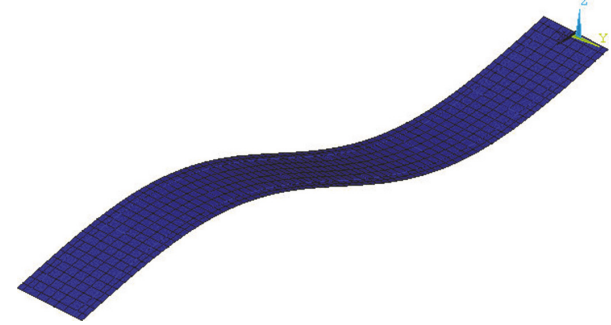

(b) 2nd vertical mode, $f_{v, 2}=10.99 \mathrm{~Hz}(+1.5 \%)$

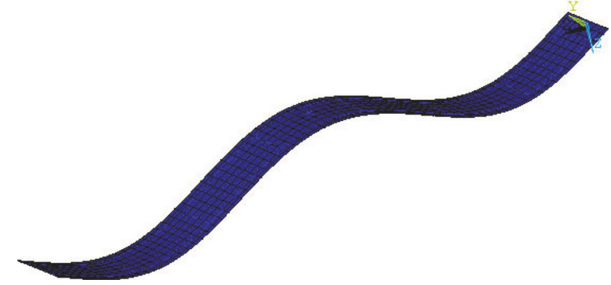

(d) 3rd vertical mode, $f_{v, 3}=24.04 \mathrm{~Hz}(+3.4 \%)$

FIGURE 5: Four modal shapes obtained from FE modal analysis. Values in parentheses represent errors between analysis and experimental results (Table 1).

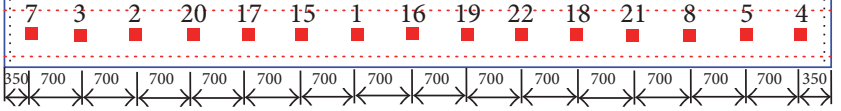

(a)

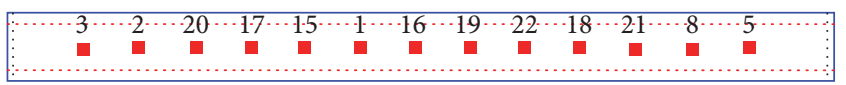

(b)

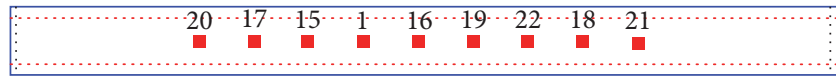

(c)

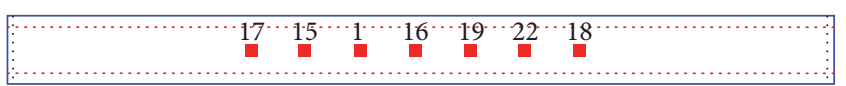

(d)

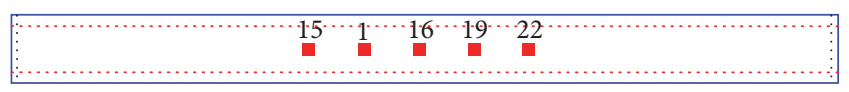

(e)

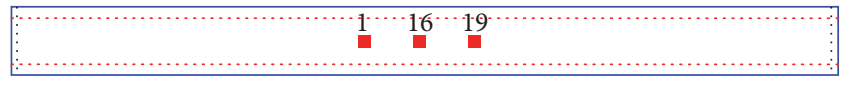

(f)

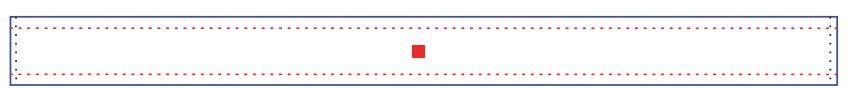

(g)

FIGURE 6: Positions of test subjects of various crowd sizes. (a) 15 persons, (b) 13 persons, (c) 9 persons, (d) 7 persons, (e) 5 persons, (f) 3 persons, and (g) single person. Note. all dimensions are in $\mathrm{mm}$.
TABLE 2: Test subject data.

\begin{tabular}{|c|c|c|c|c|}
\hline Test subject & Gender & Age (year) & Height (m) & Body mass $(\mathrm{kg})$ \\
\hline 1 & $\mathrm{M}$ & 21 & 1.80 & 88.5 \\
\hline 2 & M & 20 & 1.73 & 61.5 \\
\hline 3 & $\mathrm{M}$ & 20 & 1.74 & 65.8 \\
\hline 4 & M & 20 & 1.72 & 60.0 \\
\hline 5 & M & 20 & 1.74 & 71.1 \\
\hline 6 & M & 22 & 1.72 & 64.9 \\
\hline 7 & M & 21 & 1.68 & 65.5 \\
\hline 8 & M & 21 & 1.76 & 56.0 \\
\hline 9 & M & 21 & 1.75 & 67.8 \\
\hline 10 & $\mathrm{M}$ & 20 & 1.72 & 67.8 \\
\hline 11 & M & 22 & 1.73 & 61.0 \\
\hline 12 & M & 21 & 1.76 & 68.2 \\
\hline 13 & M & 22 & 1.70 & 57.0 \\
\hline 14 & M & 22 & 1.75 & 80.1 \\
\hline 15 & M & 21 & 1.75 & 87.6 \\
\hline 16 & M & 20 & 1.83 & 87.2 \\
\hline 17 & M & 20 & 1.75 & 83.0 \\
\hline 18 & M & 21 & 1.70 & 73.6 \\
\hline 19 & M & 22 & 1.75 & 72.9 \\
\hline 20 & $\mathrm{~F}$ & 20 & 1.60 & 49.1 \\
\hline 21 & $\mathrm{~F}$ & 21 & 1.52 & 46.2 \\
\hline 22 & M & 21 & 1.72 & 49.6 \\
\hline 23 & $\mathrm{M}$ & 25 & 1.83 & 82.5 \\
\hline [Mean, STD] & & {$[21.04,1.15]$} & {$[1.73,0.07]$} & {$[68.13,12.49]$} \\
\hline
\end{tabular}

Note. $\mathrm{F}=$ female; $\mathrm{M}=$ male; $\mathrm{STD}=$ standard deviation 


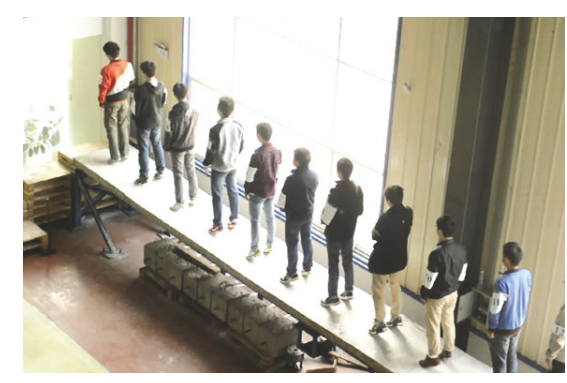

(a) Heel raised

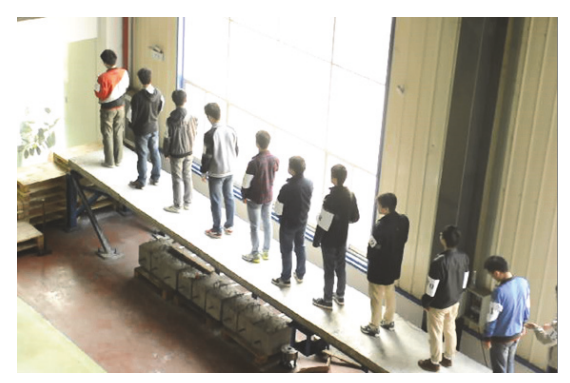

(b) Straight-knees posture

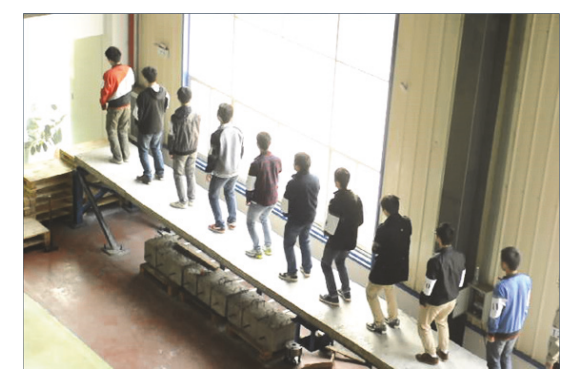

(c) Bent-knees posture

FIgURE 7: Test scenarios for stationary cases using heel-impact method.

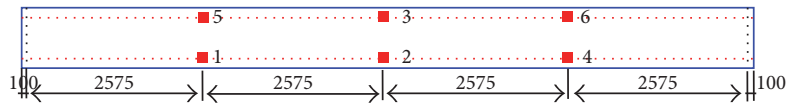

FIgURE 8: Position of the measuring points. Note. Red square depicts location of measuring points. All dimensions are in $\mathrm{mm}$.

Six accelerometers were placed on the lower flange of the I-section beam to measure the vertical acceleration responses of the bridge: measuring points 2 and 3 on the mid-span and measuring points $1,4,5$, and 6 on the quarter-span, respectively, that is, three points per side, as shown in Figure 8.

2.3. Methodology and Results. For each test, vibration signals were recorded and only the free decay responses were selected to calculate natural frequency and damping. As the vibration frequencies of the bridge are sparsely spaced (see Table 1), the responses of free vibration signals could be decomposed at each dominating component using a band-pass filtering method. Each dominating harmonic consisted of a single frequency component and can be treated as a generalized SDOF system. The damping ratio of the SDOF system can be estimated using the logarithmic decrement method.

Figure 9 shows examples of recorded mid-span acceleration responses of the bridge in the time and frequency domains from single-person tests for straight-knees and bent-knees postures. It is clear that acceleration of the bridge increases sharply when the heels of TS suddenly dropped on the deck; then it gradually decreases in a free attenuation manner when the TS is totally attached on the deck. Greater structural damping could be observed for the bent-knees posture compared with the straight-knees posture. As the impact position is in mid-span, the responses of the bridge are dominated by the first vertical frequency component.

Figure 10 describes the Fourier spectra of all test plots obtained on measuring point 1 for case of single TS with straight-knees posture. As shown in Figure 10(b), the fundamental frequency of the bridge decreases after TS's occupation. All plots indicate similar trend; even some dispersion occurs. A probable illustration for dispersion in the frequency domain could be attributed to the intersubject variability on biomechanical nature of the human body [11]. Besides, the magnitude of the spectrum varies between individuals.
Factors including differences in TSs' body weight and height of heel raise (and thus leading to different energy input), as well as human biomechanical properties, may all contribute to the discrepancy.

As the main harmonics in the frequency domain are sparsely spaced, a filtering method is employed in estimation of the damping ratio. In this study, only the first mode is considered. All signals are filtered using a band-pass fifthorder Butterworth filter. The cut-off frequency of the filter is 1 to $4 \mathrm{~Hz}$.

Table 3 summarizes the mean value of 1st vertical bending frequency and modal damping ratio of the bridge for all test cases. The results from the equivalent mass modeling are also given in the table for comparison purpose.

It is clear that the experimental results show a decrease in natural frequency and an increase in modal damping ratio of the bridge as the number of TSs increases. As expected, results from the equivalent mass modeling indicate a decrease in natural frequency with increasing number of occupants. The equivalent mass model can capture the variation in fundamental natural frequency but it cannot illustrate the significant increase in structural damping. The results from straight-knees and bent-knees postures also indicate a decrease in the natural frequency, similar to that of the equivalent mass model. For straight-knees posture, the modal damping ratio increases from $0.94 \%$ (for single TS) to $1.45 \%$ (for $13 \mathrm{TSs}$ ). For bent-knees posture, the modal damping ratio of the structure monotonously increases from 2.2\% (for single TS) to $9.57 \%$ (for 15 TSs). Moreover, one can observe that the fundamental frequency of the bridge is not sensitive to the postures of the occupants; however, it is noteworthy that the modal damping ratio of the occupied structure is very sensitive to the postures of the occupants. Much bigger values of the structural modal damping ratio could be observed for bent-knees posture than straight-knees posture under the same number of occupants. This finding is in accordance with the predictions in Figure 14(a), which will be interpreted later.

It should be noted that only the modal damping ratios of the occupied bridge are presented here. The individual contribution of material damping, structural damping, and the influence of reinforcement has not been quantified in the current study due to the limitation of test equipment. Generally, the damping in a civil engineering structure can be composed of the following contributions: material damping, 


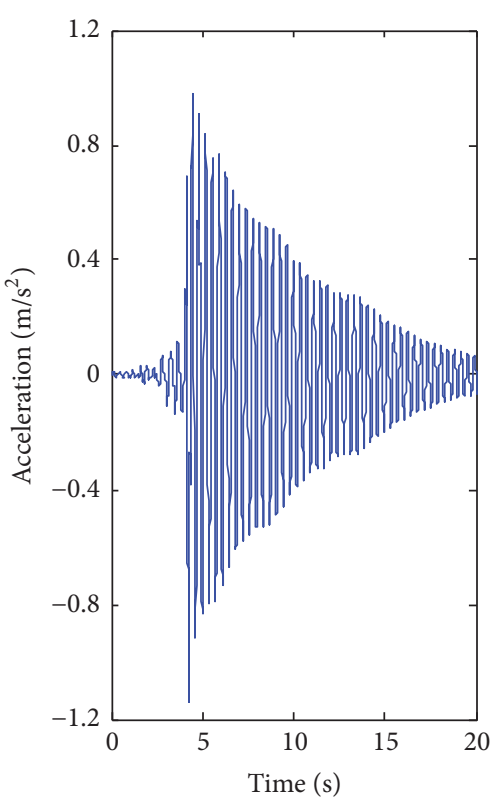

(a)

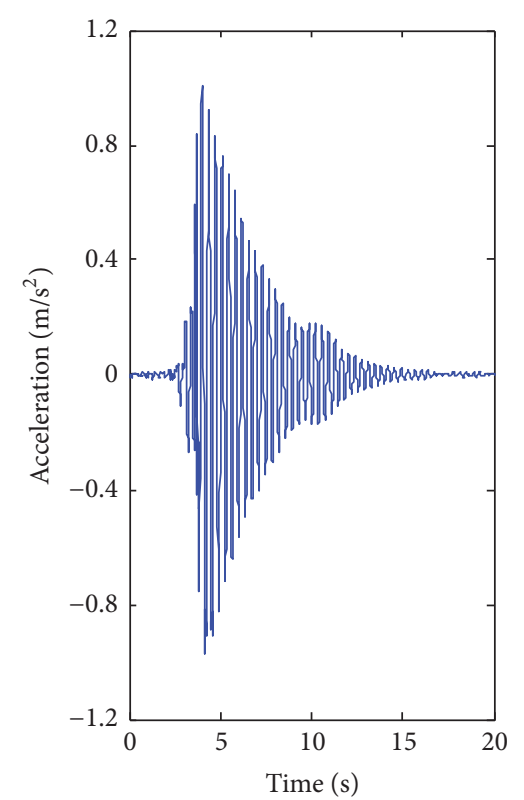

(b)

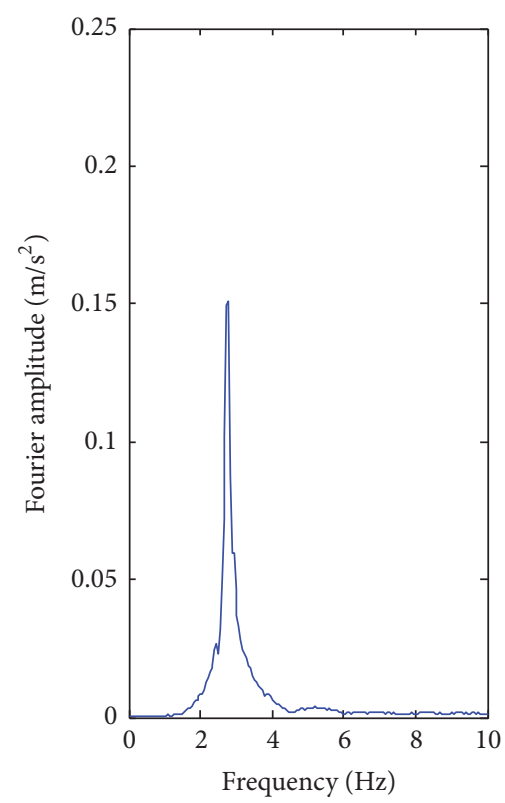

(d)

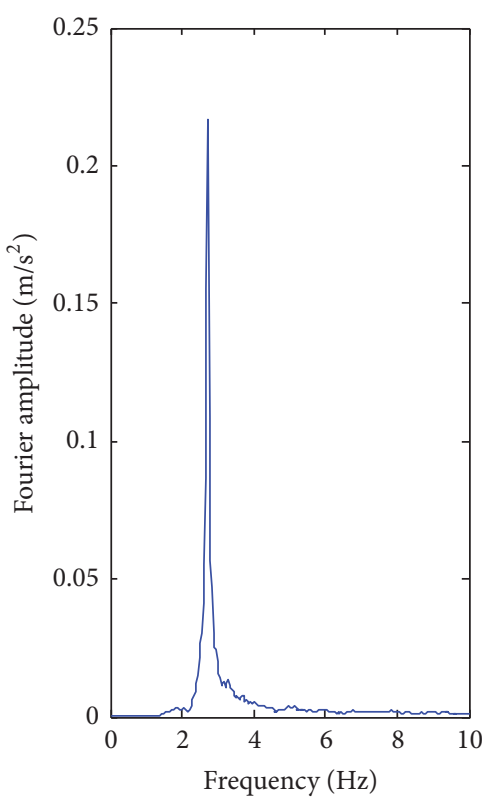

(c) single-person test.

contact-surface damping, and structural damping [35-39]. Material damping is the energy dissipation within a material, due to deformation and/or displacement. Its physical causes are heat flows induced by deformation, slip effects, and microplastic deformations [35]. Contact-surface damping is caused by relative motions in the contact surfaces of joined components such as screwed, riveted, and clamped joints [35]. Structural damping includes the energy release to the surrounding medium, for example, bedding damping or slides [35]. In the following study, the authors will spare more effort on the damping issue to improve the results.

\section{Theoretical Modeling}

In this section, an analytical model of standing peoplestructure interaction system is developed.

The following assumptions are made before the derivation:

(1) The bridge can be treated as a simply supported Bernoulli-Euler beam, having a constant cross section. The span length, area of the cross section, flexural rigidity, and density are $L, A, \mathrm{EI}$, and $\rho$, respectively. 


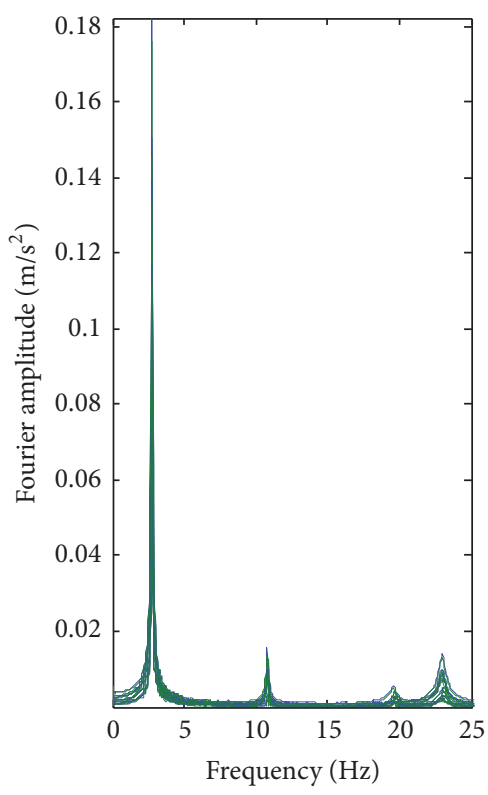

(a)

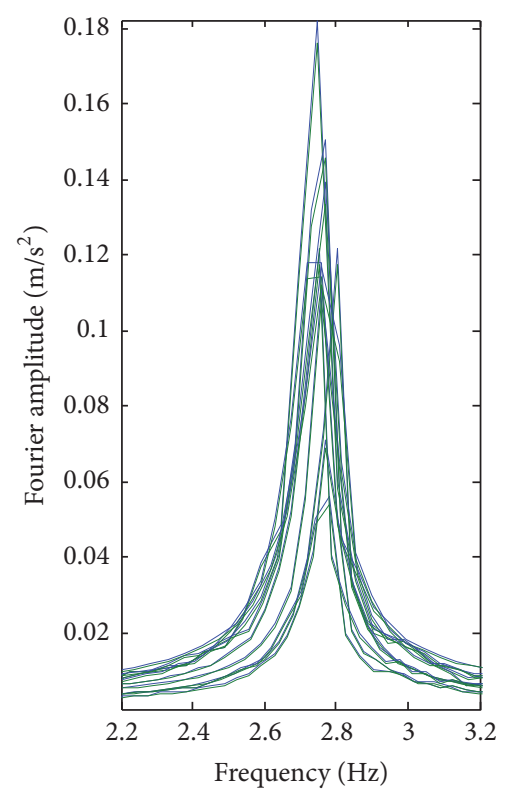

(b)

Figure 10: Fourier spectra of all test plots obtained on measuring point 1 for single person with straight-knees posture. (a) Frequency components up to $25 \mathrm{~Hz}$ and (b) enlarged view: 2.2 to $3.2 \mathrm{~Hz}$.

TABLE 3: First vertical bending frequency and modal damping ratio of the bridge.

\begin{tabular}{|c|c|c|c|c|c|c|}
\hline \multirow{2}{*}{$\begin{array}{l}\text { Number of } \\
\text { occupants }\end{array}$} & \multirow{2}{*}{$\begin{array}{c}\text { Mass ratio } \\
\text { (occupants/bridge) }\end{array}$} & \multirow{2}{*}{$\begin{array}{l}\text { Equivalent mass } \\
\text { Frequency }(\mathrm{Hz})\end{array}$} & \multicolumn{2}{|c|}{ Stand with straight knees } & \multicolumn{2}{|c|}{ Stand with bent knees } \\
\hline & & & $\begin{array}{c}\text { Frequency } \\
(\mathrm{Hz})\end{array}$ & $\begin{array}{c}\text { Modal damping ratio } \\
(\%)\end{array}$ & $\begin{array}{l}\text { Frequency } \\
(\mathrm{Hz})\end{array}$ & $\begin{array}{c}\text { Modal damping ratio } \\
(\%)\end{array}$ \\
\hline 0 & 0 & 2.82 & 2.83 & 0.42 & 2.83 & 0.42 \\
\hline 1 & 0.025 & 2.73 & 2.73 & 0.94 & 2.73 & 2.20 \\
\hline 3 & 0.071 & 2.62 & 2.60 & 1.05 & 2.63 & 5.61 \\
\hline 5 & 0.110 & 2.54 & 2.57 & 1.23 & 2.59 & 7.55 \\
\hline 7 & 0.155 & 2.48 & 2.48 & 1.43 & 2.50 & 8.16 \\
\hline 9 & 0.182 & 2.46 & 2.42 & 1.42 & 2.47 & 8.38 \\
\hline 13 & 0.255 & 2.43 & 2.41 & 1.45 & 2.44 & 9.19 \\
\hline 15 & 0.291 & 2.42 & 2.40 & 1.44 & 2.42 & 9.57 \\
\hline
\end{tabular}

Note. The results of equivalent mass model were obtained using the FE model attached with equivalent mass.

(2) The single human body could be modeled as a SDOF spring-mass-damper (SMD) system.

(3) The damping of the empty beam is relatively small compared with the human body and is ignored in this study.

(4) The biomechanical properties of human body are very complex, depending on postures, vibration level of the surrounding environment, and many others [1]. Besides, it differs among individuals. So it is really challenging to identify a determined value for a given posture for each individual. A statistical value for a certain posture derived from statistical test data sounds more realistic and meaningful. So in this study an average natural frequency and damping ratio of each posture of the standing people are used for all individuals.
The problem considered here can be described by using Figure 11.

For simply supported beam, the normalized $j$ th modal shape of the beam is

$$
\varphi_{j}(x)=C_{1} \sin \left(\frac{j \pi x}{L}\right),
$$

where $L$ is the span length of the beam and the constant $C_{1}$ is obtained by setting the modal mass to unity:

$$
\int_{0}^{L} \rho A \varphi_{j} \varphi_{k} d x= \begin{cases}1 & \text { if } j=k \\ 0 & \text { if } j \neq k\end{cases}
$$

The displacement of the beam can be obtained using modal superposition method: 


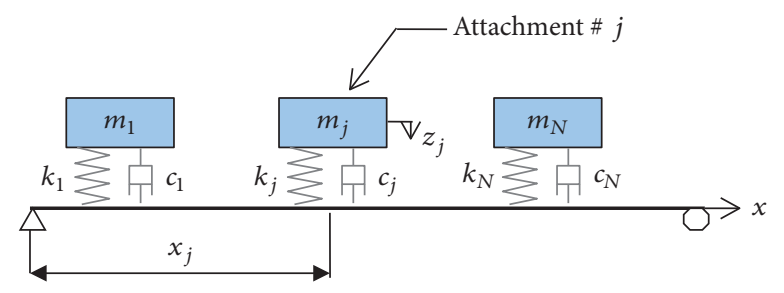

FIGURE 11: The model of human-beam coupled system.

$$
w(x, t)=\sum_{j=1}^{J} \varphi_{j}(x) q_{j}(t)
$$

where $J$ is the number of terms in the series.

The kinetic and potential energies of the system in Figure 11 are, respectively,

$$
\begin{aligned}
T & =\frac{1}{2} \int_{0}^{L} \rho A \dot{w}(x, t)^{2} d x+\frac{1}{2} \sum_{j=1}^{N} m_{j} \dot{z}_{j}^{2}=\frac{1}{2} \\
& \cdot \sum_{j=1}^{J} \sum_{k=1}^{J}\left(\int_{0}^{L} \rho A \varphi_{j} \varphi_{k} d x\right) \dot{q}_{j} \dot{q}_{k}+\frac{1}{2} \sum_{j=1}^{N} m_{j} \dot{z}_{j}^{2} . \\
V & =\frac{1}{2} \int_{0}^{L} \mathrm{EI}\left(\frac{\partial^{2} w}{\partial x^{2}}\right)^{2} d x+\frac{1}{2} \sum_{s=1}^{N} k_{s}\left(w\left(x_{s}, t\right)-z_{s}\right)^{2} \\
& =\frac{1}{2} \sum_{j=1}^{J} \sum_{k=1}^{J}\left(\int_{0}^{L} \mathrm{EI} \frac{d^{2} \varphi_{j}}{d x^{2}} \frac{d^{2} \varphi_{k}}{d x^{2}} d x\right. \\
& \left.+\sum_{s=1}^{N} k_{s} \varphi_{j}\left(x_{s}\right) \varphi_{k}\left(x_{s}\right)\right) q_{j} q_{k}-\sum_{s=1}^{N} \sum_{k=1}^{J} k_{s} \varphi_{k}\left(x_{s}\right) q_{k} z_{s} \\
& +\frac{1}{2} \sum_{j=1}^{N} k_{s} z_{s}^{2}
\end{aligned}
$$

The Rayleigh dissipation function is

$$
\begin{aligned}
D= & \frac{1}{2} \sum_{s=1}^{N} c_{s}\left(\dot{w}(x, t)-\dot{z}_{s}\right)^{2} \\
= & \frac{1}{2} \sum_{s=1}^{N} c_{s}\left[\sum_{j=1}^{J} \sum_{k=1}^{J} \varphi_{j}\left(x_{s}\right) \varphi_{k}\left(x_{s}\right) \dot{q}_{j} \dot{q}_{k}\right] \\
& -\sum_{s=1}^{N} \sum_{k=1}^{J} c_{s} \varphi_{k}\left(x_{s}\right) \dot{q}_{k} \dot{z}_{s}+\frac{1}{2} \sum_{s=1}^{N} c_{s} \dot{z}_{s}^{2} .
\end{aligned}
$$

Using the representation of $T, V$, and $D$, the motion equation of the system in Figure 11 can be obtained by employing Lagrange's equations. The equation of motion is given as

$$
M \ddot{q}+C \dot{q}+K q=0,
$$

where $\mathbf{M}, \mathbf{C}, \mathbf{K}$, and $\mathbf{q}$ are defined as

$$
\begin{aligned}
& \mathbf{M}=\left[\begin{array}{cc}
{\left[\delta_{i j}\right]_{J \times J}} & {[0]_{J \times N}} \\
{[0]^{T}{ }_{N \times J}} & {\left[\delta_{r s} m_{s}\right]_{N \times N}}
\end{array}\right] \\
& \mathbf{C}=\left[\begin{array}{cc}
{\left[\sum_{s=1}^{N} c_{s} \varphi_{i}\left(x_{s}\right) \varphi_{j}\left(x_{s}\right)\right]_{J \times J}} & {\left[-c_{s} \varphi_{j}\left(x_{s}\right)\right]_{J \times N}} \\
{\left[-c_{s} \varphi_{j}\left(x_{s}\right)\right]_{N \times J}^{T}} & {\left[\delta_{r s} c_{s}\right]_{N \times N}}
\end{array}\right]
\end{aligned}
$$

K

$$
=\left[\begin{array}{cc}
{\left[\delta_{i j} \omega_{j}^{2}+\sum_{s=1}^{N} k_{s} \varphi_{i}\left(x_{s}\right) \varphi_{j}\left(x_{s}\right)\right]_{J \times J}} & {\left[-k_{s} \varphi_{j}\left(x_{s}\right)\right]_{J \times N}} \\
{\left[-k_{s} \varphi_{j}\left(x_{s}\right)\right]_{N \times J}^{T}} & {\left[\delta_{r s} k_{s}\right]_{N \times N}}
\end{array}\right],
$$

$\mathbf{q}=\left\{\begin{array}{l}\left\{q_{j}\right\}_{J \times 1} \\ \left\{z_{s}\right\}_{N \times 1}\end{array}\right\}$,

where $i, j=1,2, \ldots, J$ and $r, s=1,2, \ldots, N$.

\section{Model Validation}

4.1. Tracking Dynamic Properties of the System Using StateSpace Method. For (6), the dynamic characteristics of the system could be obtained using the state-space method. Equation (6) can be converted to state-space form as follows [40]:

$$
\mathbf{S} \dot{\mathbf{x}}-\mathbf{R x}=\mathbf{0}
$$

where $\mathbf{S}, \mathbf{R}$, and $\mathbf{x}$ are defined as

$$
\begin{aligned}
& \mathbf{S}=\left[\begin{array}{cc}
-\mathbf{K} & \mathbf{0} \\
\mathbf{0} & \mathbf{M}
\end{array}\right] \\
& \mathbf{R}=\left[\begin{array}{cc}
\mathbf{0} & -\mathbf{K} \\
-\mathbf{K} & -\mathbf{C}
\end{array}\right] \\
& \mathbf{X}=\left\{\begin{array}{c}
\mathbf{q} \\
\dot{\mathbf{q}}
\end{array}\right\} .
\end{aligned}
$$

The solution of (8) is obtained by substituting $\{\mathbf{x}\}=\{\phi\} e^{\lambda t}$ into (8), resulting in the symmetric generalized eigenvalue problem:

$$
\left(\mathbf{R}-\lambda_{n} \mathbf{S}\right)\left\{\phi_{n}\right\}=\{0\}
$$

in which $\lambda_{n}$ and $\left\{\phi_{n}\right\}$ are the $n$th complex eigenvalue and its corresponding eigenvector of the $2(N+J)$ eigensolutions.

Eigenvalues $\lambda_{n}$ of (10) would be obtained using complex modal analysis method [41] and the natural frequencies $f_{n}$ and damping ratios $\zeta_{n}$ can be given as [26]

$$
\begin{aligned}
& f_{n}=\frac{1}{2 \pi}\left|\lambda_{n}\right| ; \\
& \zeta_{n}=\frac{-\operatorname{Re}\left(\lambda_{n}\right)}{\left|\lambda_{n}\right|} .
\end{aligned}
$$



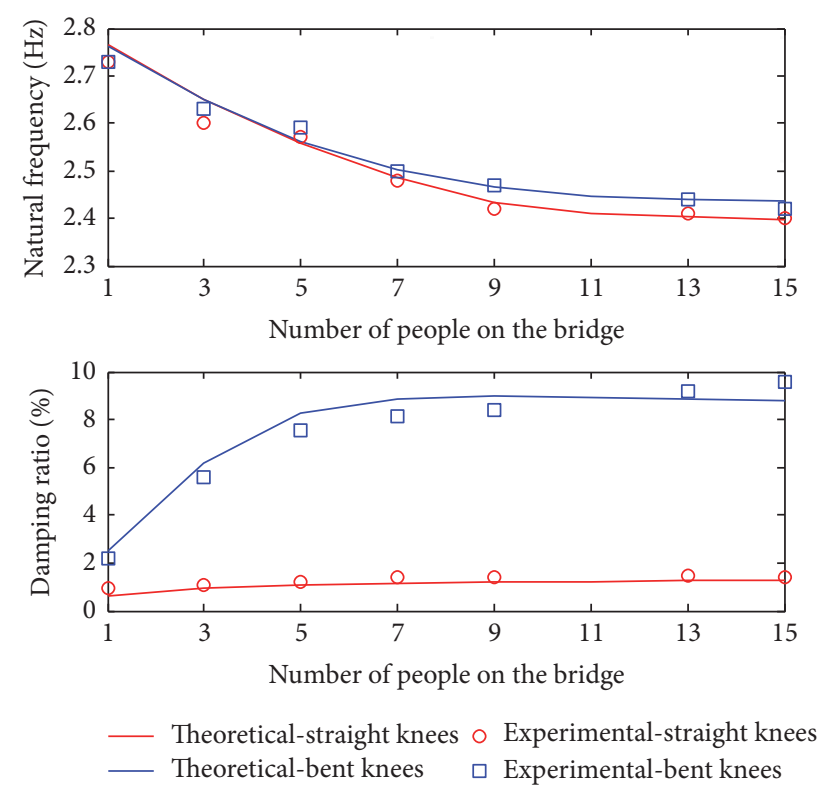

FIGURE 12: Comparison between theoretical and experimental results.

4.2. Comparisons of Theoretical Results with Experimental Data. Parameters used in the numerical study are briefly illustrated below. The natural frequencies of $5.5 \mathrm{~Hz}$ in the normal posture and $2.75 \mathrm{~Hz}$ in the legs bent posture for standing human body suggested by Matsumoto and Griffin [20] are used. Due to the complex nature of the human body and the availability of experimental data in the literature, an average modal damping ratio $\zeta_{H}=0.4$ suggested by Griffin [1] was used for both normal standing posture and knees bent posture. The span length of the bridge $L=10.3 \mathrm{~m}$, and its total mass is $3500 \mathrm{~kg}$. Occupations' locations $\left(x_{j}\right)$ of each test scenario can be found in Figure 6, and the body mass of each individual can be found in Table 2.

Figure 12 shows the comparison results of dynamic properties of the bridge between experimental data and simulated ones. It is clear that the theoretical results show similar trend to that of the experimental data for both natural frequency and modal damping ratio. A decrease in natural frequency and an increase in modal damping ratio are observed as the number of occupants increases. The simulated natural frequency and modal damping ratio of the occupied bridge agree well in general with the experimental results; even some discrepancy occurs. This discrepancy could be attributed to the assumption of identical properties of the vertical human body of each individual, which may differ from the actual cases. In general, the theoretical model developed in this paper can give a promising prediction of the variations of dynamic properties of the structure. Hence, the model can be used as an alternative to modeling the HSI. In the following analysis, the model is employed to further discuss the effect of some key factors on dynamic properties of the occupied structure.

\section{Influence of Human Parameters: Numerical Results}

Previous studies show that the occupants to structure mass ratios, occupants to structure frequency ratios, and many others will affect the dynamic properties of the occupied structures $[11,26]$. Compared to the above-mentioned factors, the influence of human body parameters (especially damping properties and natural frequencies of standing human body) on dynamic properties of the occupied structure is rarely concerned. To this end, in this section, the effect of the human parameters on dynamic properties of the structure is discussed in detail using the model developed in Section 3.

Numerical example related to a real single-span steelconcrete composite bridge [42] is considered. The basic properties of the bridge are as follows: span length $16.2 \mathrm{~m}$; total mass $13432 \mathrm{~kg}$; the first two natural frequencies of the bridge 2.48 and $7.78 \mathrm{~Hz}$.

The occupants are assumed to be uniformly distributed on the full length of the bridge. The mass, stiffness, and damping properties of the human body are assumed to be identical for each individual. The bridge is approximately treated as a simply supported beam, and the $n$th mode shape of the beam is given by $\phi_{n}(x)=\sin (n \pi x / L)$. In engineering practice, we usually focus on the lower modes of the structure, so only the lowest two modes are considered herein.

5.1. Effect of Damping Properties of the Human Body. As aforementioned, the damping properties of the human body vary depending on postures, vibration amplitude of the surrounding environment, and some other factors. An average damping ratio ranging from 0.3 to 0.5 for standing posture is suggested by Griffin [1]. To examine the effect of damping properties of human body on dynamic characteristics of the structure, three damping ratios of the standing human body, $\xi_{H}=0.3,0.4$, and 0.5 , are considered. The occupants are assumed to be uniformly distributed on the full length of the bridge with the density of $\rho=2 \mathrm{p} / \mathrm{m}^{2}$. An average body mass of $70 \mathrm{~kg}$ and natural frequency of $5.5 \mathrm{~Hz}$ are used.

Figure 13 shows the first two dimensionless natural frequencies and modal damping ratios of the bridge with respect to different damping properties of the human body. It is clear that the damping properties of the human body contribute little to the natural frequencies of the occupied bridge. For different body modal damping ratios, the frequency of the occupied bridge remains almost the same for the first mode (0.9 times of the empty structure, i.e., a $-10 \%$ decrease), and the variation for the second mode is also small ( 0.97 to 1.01 for the second mode), which indicates that the natural frequencies of the occupied bridge are not sensitive to the damping properties of the human body. An increase in modal damping ratios could be observed for the first two modes. In the parameter scope of the present study, the variation of the damping ratio is within the scope of 1.5 to 1.8 for the first mode and 15.8 to 17 for the second mode.

5.2. Effect of Natural Frequency of the Human Body. People with different postures (normal standing, standing with bent knees, standing with one leg, etc.) have different natural 

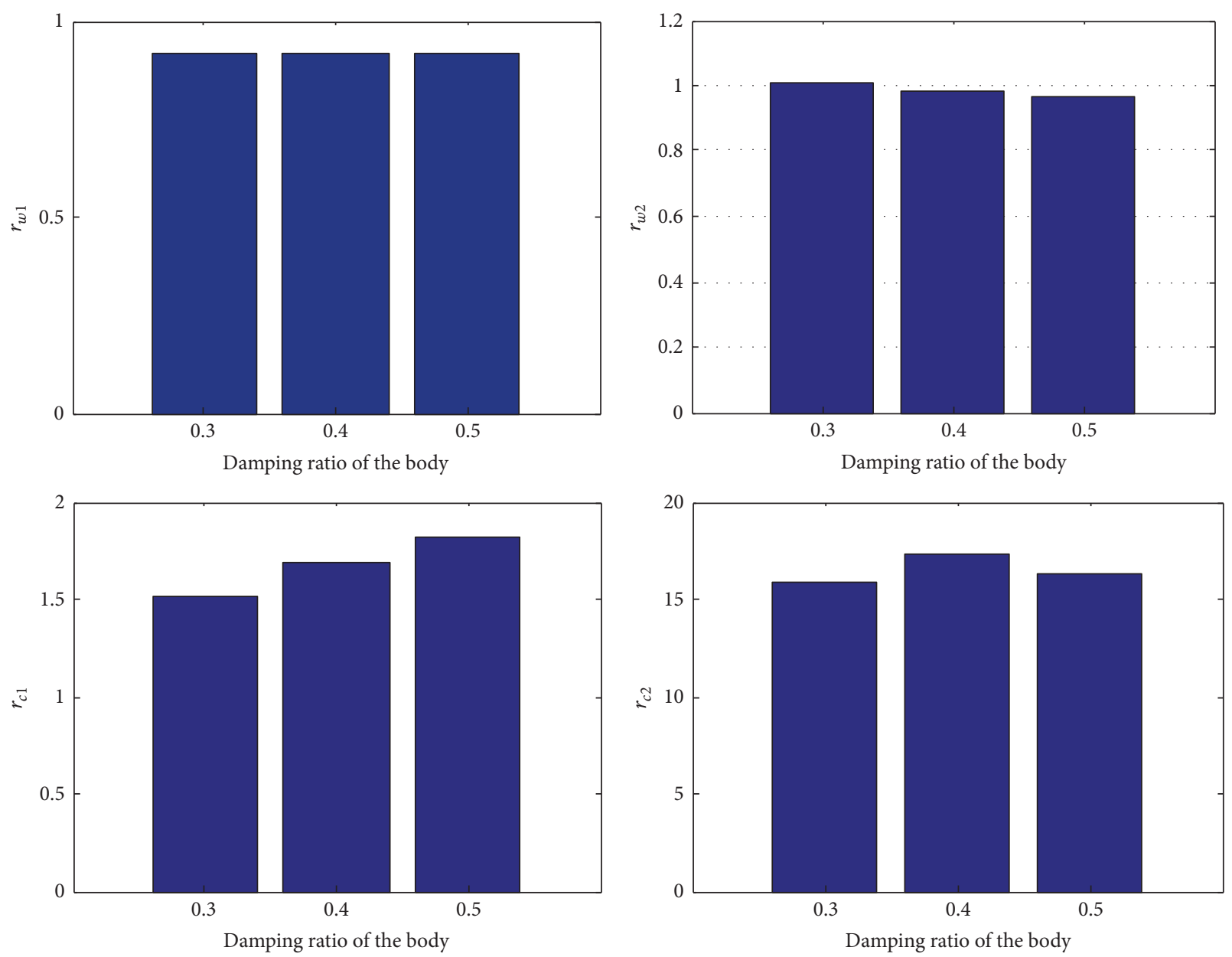

(a)

(b)

FIGURE 13: First two natural frequencies and damping ratios of the bridge against different damping properties of the human body: first mode (a) and second mode (b).

frequencies [1]. To examine the effect of natural frequency of human body on dynamic characteristics of the occupied structure, three natural frequencies of the standing human body, $\omega_{H}=2.75$ (bent-knees posture), 3.5 (one-leg posture), and $5.5 \mathrm{~Hz}$ (straight-knees posture), are considered. The occupants are assumed to be uniformly distributed on the full length of the bridge with the density of $2.0 \mathrm{p} / \mathrm{m}^{2}$. An average body mass of $70 \mathrm{~kg}$ and damping ratio of 0.4 are used.

Figure 14 illustrates the first two dimensionless natural frequencies and modal damping ratios of the bridge with respect to different natural frequencies of the human body.

As shown in Figure 14, the lowest two frequencies of the occupied bridge are not sensitive to the natural frequencies of the human body. However, the modal damping ratios of the occupied bridge are very sensitive to the natural frequencies of the human body. In the given parameter scope, the frequency of the bridge with occupants is 0.9 times that of the empty structure for the first mode (i.e., a $-10 \%$ decrease) and 0.98 to 1 for the second mode. The variation of the modal damping ratio is within the scope of 1.7 to 9.6 for the first mode and 5.7 to 17 for the second mode.
Comparison of the three body natural frequencies indicates that the smaller the body natural frequencies, the bigger the first modal damping ratios and the smaller the second modal damping ratios. This can account for the experimental results presented in Table 3 and Figure 12. As shown in Table 3 and Figure 12, the first natural frequency of the occupied bridge is not sensitive to different postures, while much bigger values of modal damping ratio were observed for the bent-knees posture compared with the straight-knees posture. Moreover, a general decrease in natural frequencies and an increase in modal damping ratios for the first two modes could be observed from Figure 14 although the variation of the natural frequencies of the second mode is very small.

\section{Conclusions}

A purpose-built lively bridge was constructed. Model properties of the empty structure are obtained based on ambient vibration testing method. Experimental tests of the bridge attached with standing people were also conducted. A mathematic model of standing people-structure interaction system is developed and verified. 

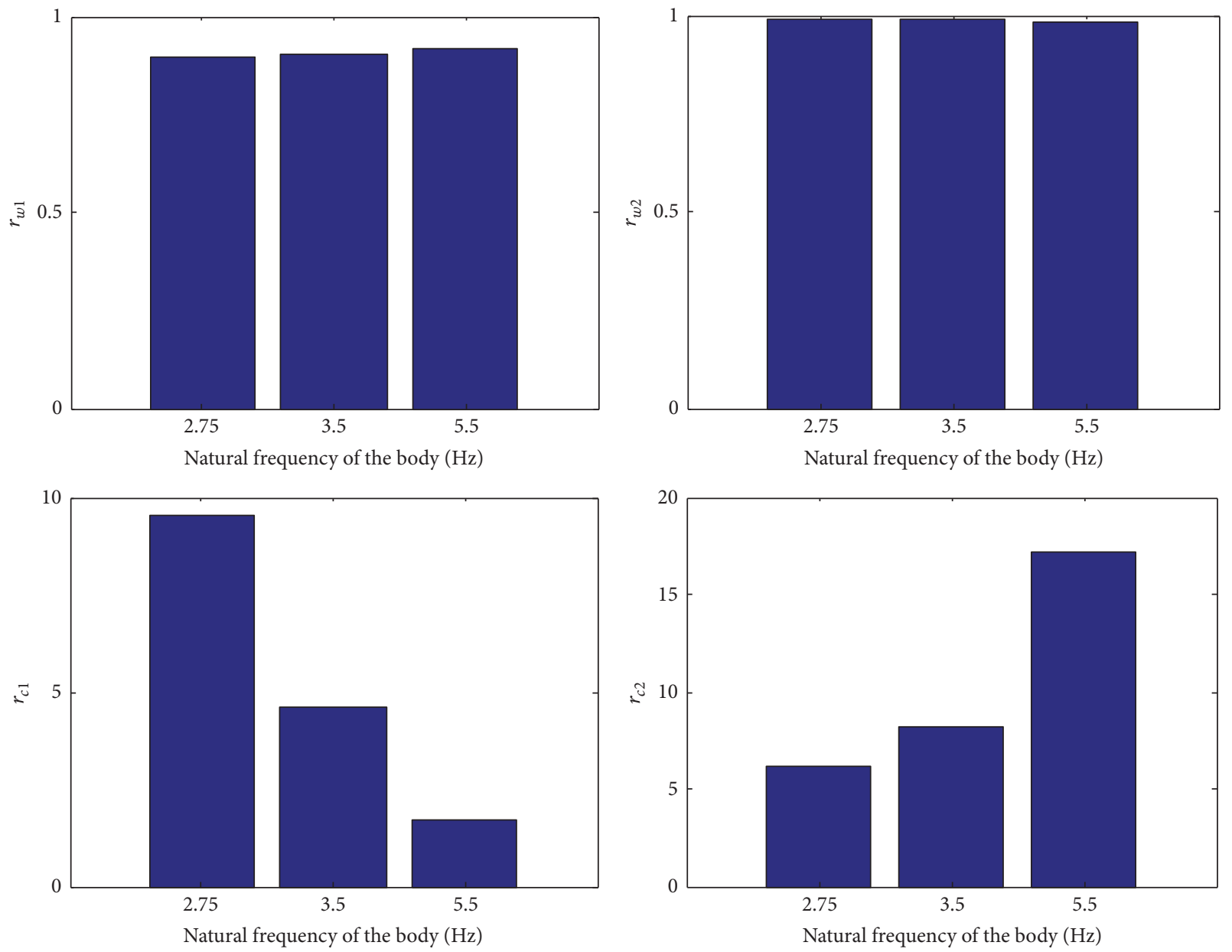

(a)

(b)

FIGURE 14: First two natural frequencies and damping ratios of the bridge against different natural frequencies of the human body: first mode (a) and second mode (b).

It is shown that the model developed in this paper can effectively illustrate the experimental observations. Hence, the model can be used as an alternative to modeling the HSI.

Numerical examples show that the modal properties of the human body contribute remarkably to the structural damping but little to the natural frequencies of the occupied structure.

\section{Conflicts of Interest}

The authors declare that they have no conflicts of interest.

\section{Acknowledgments}

This research was sponsored by National Natural Science Foundation of China (Grant no. 51508431), China Postdoctoral Science Foundation (Grant no. 2015M582288), and scholarship from China Scholarship Council (Grant no. 201606955008).

\section{References}

[1] M. J. Griffin, Handbook of Human Vibration, Academic Press, London, 1990.

[2] Y. Fujino, B. M. Pacheco, S.-I. Nakamura, and P. Warnitchai, "Synchronization of human walking observed during lateral vibration of a congested pedestrian bridge," Earthquake Engineering \& Structural Dynamics, vol. 22, no. 9, pp. 741-758, 1993.

[3] P. Dallard, A. J. Fitzpatrick, A. Flint et al., "The London millennium footbridge," Structural Engineering International, vol. 79, no. 22, pp. 17-33, 2001.

[4] P. Dallard, T. Fitzpatrick, A. Flint et al., "London millennium bridge: pedestrian-induced lateral vibration," Journal of Bridge Engineering, vol. 6, no. 6, pp. 412-417, 2001.

[5] J. H. Macdonald, "Lateral excitation of bridges by balancing pedestrians," Proceedings of the Royal Society A Mathematical, Physical and Engineering Sciences, vol. 465, no. 2104, pp. 10551073, 2009.

[6] B. R. Ellis and T. Ji, "Human-structure interaction in vertical vibrations," Proceedings of the Institution of Civil Engineers Structures and Buildings, vol. 122, no. 1, pp. 1-9, 1997. 
[7] S. Falati, The contribution of non-structural components to the overall dynamic behaviour of concrete floor slabs [Ph.D. thesis], University of Oxford, Oxford, 1999.

[8] J. M. W. Brownjohn, "Energy dissipation from vibrating floor slabs due to human-structure interaction," Shock and Vibration, vol. 8, no. 6, pp. 315-323, 2001.

[9] R. Sachse, A. Pavic, and P. Reynolds, "Human-structure dynamic interaction in civil engineering dynamics: a literature review," Shock and Vibration, vol. 35, no. 1, pp. 3-18, 2003.

[10] J. M. W. Brownjohn, P. Fok, M. Roche, and P. Omenzetter, "Long span steel pedestrian bridge at Singapore Changi Airport-part 2: crowd loading tests and vibration mitigation measures," Structural Engineering International, vol. 82, no. 16, pp. 28-34, 2004.

[11] S. Zivanovic, A. Pavic, and P. Reynolds, "Vibration serviceability of footbridges under human-induced excitation: a literature review," Journal of Sound and Vibration, vol. 279, no. 1-2, pp. 174, 2005.

[12] P. Reynolds and A. Pavic, "Vibration performance of a large cantilever grandstand during an international football match," Journal of Performance of Constructed Facilities, vol. 20, no. 3, pp. 202-212, 2006.

[13] S. S. D. Silva and D. P. Thambiratnam, "Dynamic characteristics of steel-deck composite floors under human-induced loads," Computers \& Structures, vol. 87, no. 17-18, pp. 1067-1076, 2009.

[14] C. A. Jones, P. Reynolds, and A. Pavic, "Vibration serviceability of stadia structures subjected to dynamic crowd loads: a literature review," Journal of Sound and Vibration, vol. 330, no. 8, pp. 1531-1566, 2011.

[15] K. A. Salyards and N. C. Noss, "Experimental evaluation of the influence of human-structure interaction for vibration serviceability," Journal of Performance of Constructed Facilities, vol. 28, no. 3, pp. 458-465, 2014.

[16] K. A. Salyards and Y. Hua, "Assessment of dynamic properties of a crowd model for human-structure interaction modeling," Engineering Structures, vol. 89, pp. 103-110, 2015.

[17] Q. An, Q. Ren, H. Liu, X. Yan, and Z. Chen, "Dynamic performance characteristics of an innovative Cable Supported Beam Structure-Concrete Slab Composite Floor System under human-induced loads," Engineering Structures, vol. 117, pp. 4057, 2016.

[18] P. Dey, A. Sychterz, S. Narasimhan, and S. Walbridge, "Performance of Pedestrian-Load Models through Experimental Studies on Lightweight Aluminum Bridges," Journal of Bridge Engineering, vol. 21, no. 8, Article ID C4015005, 2016.

[19] J. Herterich and J. Schnauber, "The effect of vertical mechanical vibration on standing man," J. Low Freq. Noise Vib, vol. 11, pp. 52-60, 1992.

[20] Y. Matsumoto and M. J. Griffin, "Dynamic response of the standing human body exposed to vertical vibration: influence of posture and vibration magnitude," Journal of Sound and Vibration, vol. 212, no. 1, pp. 85-107, 1998.

[21] S. Kitazaki and M. J. Griffin, "A modal analysis of whole-body vertical vibration, using a finite element model of the human body," Journal of Sound and Vibration, vol. 200, no. 1, pp. 83102, 1997.

[22] Y. Matsumoto and M. J. Griffin, "Mathematical models for the apparent masses of standing subjects exposed to vertical wholebody vibration," Journal of Sound and Vibration, vol. 260, no. 3, pp. 431-451, 2003.
[23] T. Ji, "A continuous model for the vertical vibration of the human body in a standing position," in United Kingdom Informal Group Meeting on Human Response to Vibration, Silsoe, UK, 1995.

[24] D. Zhou, T. Ji, and W. Liu, "Dynamic characteristics of a standing human on a SDOF structure," Adv. Vib. Eng, vol. 11, pp. 83-96, 2012.

[25] D. Zhou, H. Han, T. Ji, and X. Xu, "Comparison of two models for human-structure interaction," Applied Mathematical Modelling, vol. 40, no. 5-6, pp. 3738-3748, 2016.

[26] R. Sachse, A. Pavic, and P. Reynolds, "Parametric study of modal properties of damped two-degree-of-freedom crowd-structure dynamic systems," Journal of Sound and Vibration, vol. 274, no. 3-5, pp. 461-480, 2004.

[27] S. Ivanovic, M. Trifunac D, and M. Todorovska I, "Ambient vibration test-a review," ISET Journal of Eearthquake Technology, vol. 37, no. 4, pp. 165-197, 2000.

[28] B. Jaishi and W. X. Ren, "Structural finite element model updating using ambient vibration test results," Journal of Structural Engineering, vol. 131, no. 4, pp. 617-628, 2005.

[29] P. V. Overschee and B. de Moor, "Subspace algorithms for the stochastic identification problem," in Proceedings of the 30th IEEE Conference on Decision and Control, pp. 1321-1326, Brighton, England.

[30] P. van Overschee and B. de Moor, Subspace Identification for Linear Systems: Theory Implementation Applications, Kluwer Academic Publishers, Dordrecht, The Netherlands, 1996.

[31] B. Peeters and G. de Roeck, "Reference-based stochastic subspace identification for output-only modal analysis," Mechanical Systems and Signal Processing, vol. 13, no. 6, pp. 855-878, 1999.

[32] W.-X. Ren, X.-L. Peng, and Y.-Q. Lin, "Experimental and analytical studies on dynamic characteristics of a large span cable-stayed bridge," Engineering Structures, vol. 27, no. 4, pp. 535-548, 2005.

[33] W. D. Varela and R. C. Battista, "Control of vibrations induced by people walking on large span composite floor decks," Engineering Structures, vol. 33, no. 9, pp. 2485-2494, 2011.

[34] C. M. Abeysinghe, D. P. Thambiratnam, and N. J. Perera, "Dynamic performance characteristics of an innovative Hybrid Composite Floor Plate System under human-induced loads," Composite Structures, vol. 96, pp. 590-600, 2013.

[35] H. Wiechmann, "VDI-Richtlinien (VDI 3796, Blatt 1, 2 und 3): Bestimmung von Thallium in Böden und Pflanzen. (VDI 3792, Blatt 3): Messen der Immissions-Wirkdosis von Blei in Pflanzen mit dem Verfahren der standardisierten Graskultur. Beuth-Verlag, Postfach 1145, 1000 Berlin 30 (1985)," Zeitschrift für Pflanzenernährung und Bodenkunde, vol. 150, no. 2, pp. 125125, 1987.

[36] VDI 3830 Blatt 2, Damping of materials and members-Damping of solids, vol. 10, Beuth Verlag, Berlin, Germany, 2004.

[37] Beuth Verlag, Damping of materials and members-Damping of assemblies, vol. 8, Beuth Verlag, Berlin, Germany, 2004.

[38] VDI 3830 Blatt 4, Damping of materials and members-Models for damped structures, Beuth Verlag, Berlin, Germany, 2005.

[39] VDI 3830 Blatt 5, Damping of materials and membersExperimental techniques for the determination of damping characteristics, Beuth Verlag, Berlin, 2005.

[40] M. V. Drexel and J. H. Ginsberg, "Modal overlap and dissipation effects of a cantilever beam with multiple attached oscillators," Journal of Vibration and Acoustics, vol. 123, no. 2, pp. 181-187, 2001. 
[41] K. A. Foss, "Co-ordinates which uncouple the equations of motion of damped linear dynamic systems," vol. 25, pp. 361-364, 1958.

[42] S. Zivanovic, R. P. Johnson, H. V. Dang, and J. Dobrić, "Design and construction of a very lively bridge," in Proceedings of the 31st IMAC, A Conference on Structural Dynamics, 2013, pp. 371380, USA, February 2013. 


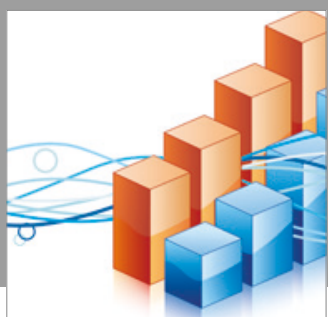

Advances in

Operations Research

vatersals

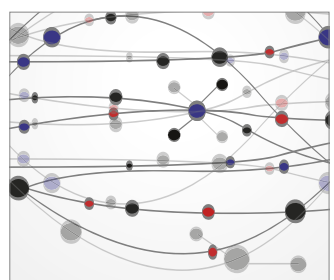

\section{The Scientific} World Journal
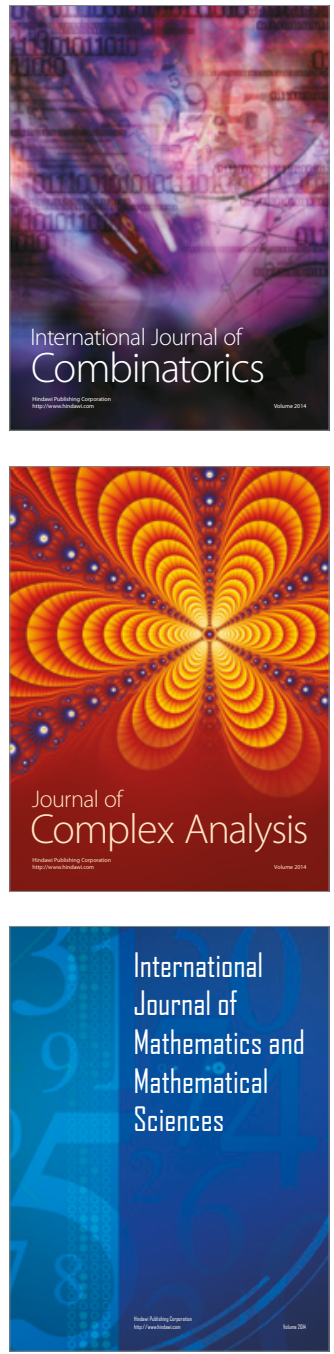
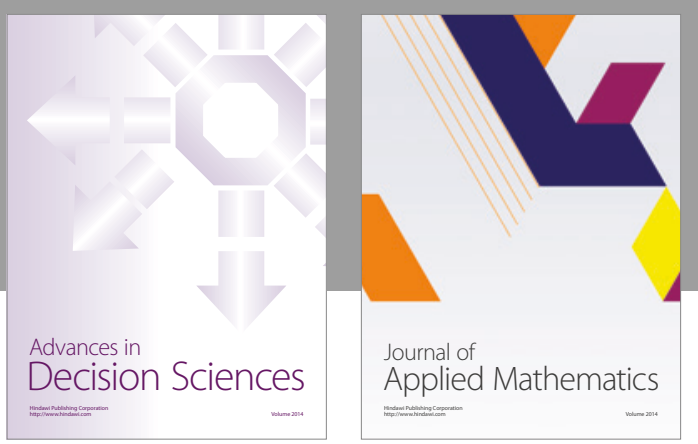

Algebra

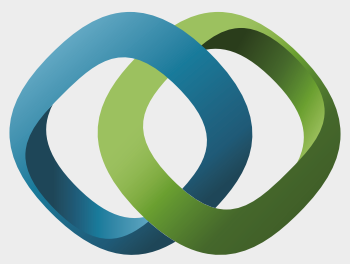

\section{Hindawi}

Submit your manuscripts at

https://www.hindawi.com
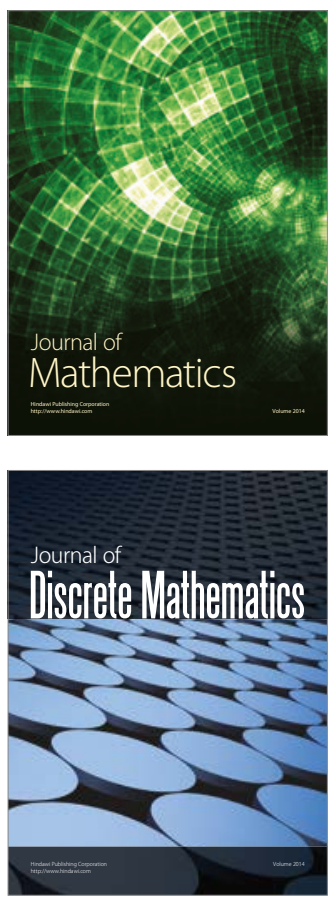

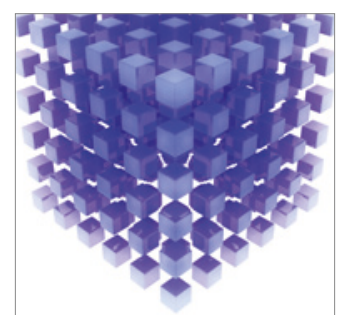

Mathematical Problems in Engineering
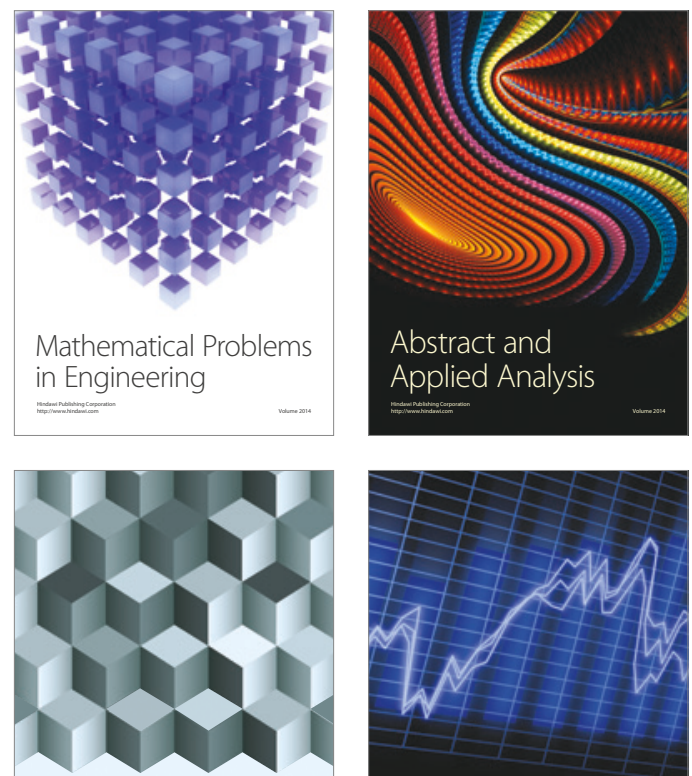

Journal of

Function Spaces

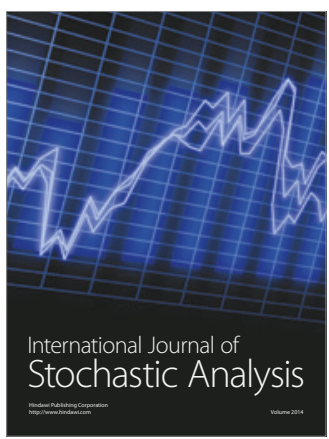

Probability and Statistics
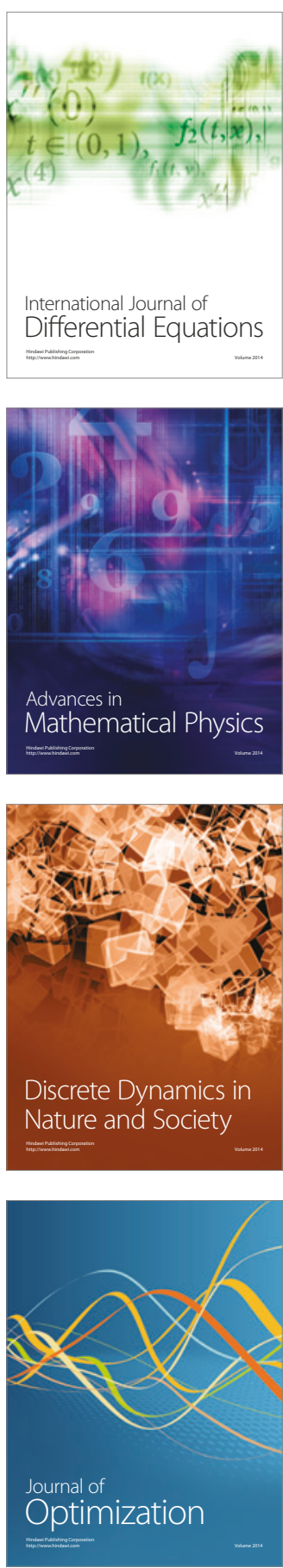